\title{
Complex processing of liquid pyrolysis products
}

\author{
Dariia Kichura, Roman Subtelnyi, Bohdan Dzinyak \\ Institute of chemistry and chemical technology, Lviv Polytechnic National University, \\ Ukraine, Lviv, St. Banderu str., E-mail: dariia.b.kichura@1pnu.ua
}

The processing of oil fractions or natural gas produces a significant amount of liquid products of pyrolysis (LPP) or cracking of hydrocarbons. Due to the increase in the capacity of pyrolysis plants, a large number of LPPs are formed, the qualified use of which is a necessary condition for ensuring the profitability and waste-freeness of ethylene. The yield of LPP, depending on the raw material and the mode of the pyrolysis process, is 20 ... 40\%. The use of LPP for the production of petroleum resins can significantly improve the technical and economic performance of ethylene plants and reduce the cost of ethylene by 20 ... 30\%. LPP fractions and their combinations are mainly used to obtain NPS.

Keywords - liquid pyrolysis products and cracking, heavy pyrolysis resin, hydrocarbons, dienes wine.

\section{Introduction}

Given the constant rise in prices for traditional hydrocarbons and all types of energy efficiency, the question of a natural or natural approach to assessing the energy efficiency of petrochemical and refining industries, along with conventional industries. It is known that any hydrocarbon obtained by refining oil, natural gas or coal is a potential raw material for chemical processes or a primary energy source. Prices for such energy and raw hydrocarbons in international markets depend on many factors: economic, social, political, and so on. Therefore, value comparisons in the choice of chemical processing of raw materials do not always give a positive result, so increasing the energy efficiency and waste-freeness of such industries does not lose its relevance.

In the pyrolysis of lower olefins by thermal pyrolysis of hydrocarbons, liquid pyrolysis products (LPPs) with a boiling point of $28-450{ }^{\circ} \mathrm{C}$ and above are formed. Pyrolysis of straightrun gasoline per 1 ton of ethylene yields 1.0 to 1.1 tons of LPP. On modern ethylene complexes RPP is divided into pyrocondensate or LPS $\left(28-200{ }^{\circ} \mathrm{C}\right)$ and VPS boiling point $200{ }^{\circ} \mathrm{C}$. LPPs and LPK obtained on ethylene plants contain valuable active, alkenyl-, vinyl aromatic and other hydrocarbons. This is, in particular, the fraction $\mathrm{C}_{5}\left(30-70{ }^{\circ} \mathrm{C}\right)$, containing isoprene, cyclopentadiene (CPD), piperylene; fraction $\mathrm{C}_{8-9}\left(130\right.$ - $\left.190{ }^{\circ} \mathrm{C}\right)$ - styrene inden, vinyltoluene.

Fraction $\mathrm{C}_{5}$ in its composition contains a significant amount of valuable new monomers, $\%$ wt .: 2025 isoprene, 20 - 25 CPD, 10 - 15 piperylene. In the pyrolysis of gaseous hydrocarbons $\mathrm{C}_{2}-\mathrm{C}_{4}$ at a temperature of $790-800{ }^{\circ} \mathrm{C}$, the contact time of $1.5 \mathrm{~s}$, the yield of the fraction $\mathrm{C}_{5}-$ the beginning of boiling $-70{ }^{\circ} \mathrm{C}$, is $2.5-3.5 \mathrm{wt} \%$. From raw materials (density $0.65-0.73 \mathrm{~g} /$ $\mathrm{cm} 3$, bromine number $100-180 \mathrm{~g} \mathrm{Br}_{2} / 100 \mathrm{~g}$, diene content $35-60 \%$ of the mass. The fraction $\mathrm{C}_{5}$ of pyrolysis of a mixture of gaseous hydrocarbons and gasoline contains 0.26 to $0.54 \%$ of the mass. Codimers DCPD with isoprene and pentadienes, isoprene 9.48 - 13.7\% wt., CPD 7.6 $11.5 \%$ wt., DCPD 1.92 - $4.29 \%$ wt. In addition, it may contain several percent oxygencontaining compounds.

The composition of the fraction $\mathrm{C}_{5}$ of atmospheric gas oil $\left(180-360{ }^{\circ} \mathrm{C}\right)$ differs little from the composition of the fraction $\mathrm{C}_{5}$ pyrolysis of gasoline, only a small content of compounds with sulfur and nitrogen. This fraction has a diene content of about $40-60 \%$ of the mass. and a very low flash point $\left(-25{ }^{\circ} \mathrm{C}\right)$. Fraction $\mathrm{C}_{8-9}$, boiling in the range of $120-200{ }^{\circ} \mathrm{C}$, contains mainly alkenylaromatic hydrocarbons and cerebral palsy. In the case of pyrrole from gaseous hydrocarbons or mixed raw materials (gaseous hydrocarbons and gasoline), the fraction is 
characterized by a high degree of aromatization and the content of non-aromatic hydrocarbons in it is $2-5 \%$ of the mass.

The composition of the fraction $\mathrm{C}_{8-9}$ pyrolysis of gasoline with increasing temperature of pyrolysis from $770-780{ }^{\circ} \mathrm{C}$ to $825-840{ }^{\circ} \mathrm{C}$ increases the content of alkenylaromatic hydrocarbons. Fraction $\mathrm{C}_{8-9}$ of pyrolysis of atmospheric gas oil $\left(810{ }^{\circ} \mathrm{C}\right.$, sulfur content $0,2 \mathrm{wt}$.) Has a high content, $\%$ wt.$:$ indene $17-23$, styrene 15-19, alkyl benzene $25-33$. Heavier raw materials yield of dienes $\mathrm{C}_{6-9}$, styrene, vinyl styrene decreases, and diene $\mathrm{C}_{5}$ is virtually unchanged. The fraction $\mathrm{C}_{9}\left(150-190{ }^{\circ} \mathrm{C}\right)$ pyrocondensate of the propylene mode of pyrolysis of gasoline in industrial plants contains $50 \%$ of the mass. reactive alkenylaromatic hydrocarbons and cerebral palsy, with increasing stiffness, the number of these compounds decreases by $9 \%$ of the mass. Fraction $\mathrm{C}_{6-7}\left(70-130^{\circ} \mathrm{C}\right)$ LPPs contains a small amount of dienes, usually 3 - 5\% wt., mostly aliphatic in nature and has no industrial interest.

The heavy pyrolysis resin (HPR) contains up to $20-25 \%$ of the mass. naphthalene and its alkyl homologues. Developed and prepared hydrogenations on the technology of the process of obtaining naphthalene from the Air Force, which will purify pyrolysis naphthalene from impurities of unsaturated and saturated hydrocarbons, which provides the possibility of separation of naphthalene from the hydrogenate by distillation with high yield from its potential content (up to $90 \%$ ) energy-intensive operations, such as crystallization, pressing.

\section{Experimental results and discussion}

Hydrogenation processes of HPR fractions using catalysts based on: Pd, Ni, Mo, Co, W will offer a number of processes for the production of tetralin, dimethylnaphthalene, acenaphthene, fluorene and other important products. An HPR recycling scheme has been developed, which will fully meet the needs for naphthalene, dark NPR, raw materials for coke and carbon black. It is expedient to expand the range of marketable products made of pyrocondensate, LPR and HPR, to improve the complex scheme of their qualified processing.

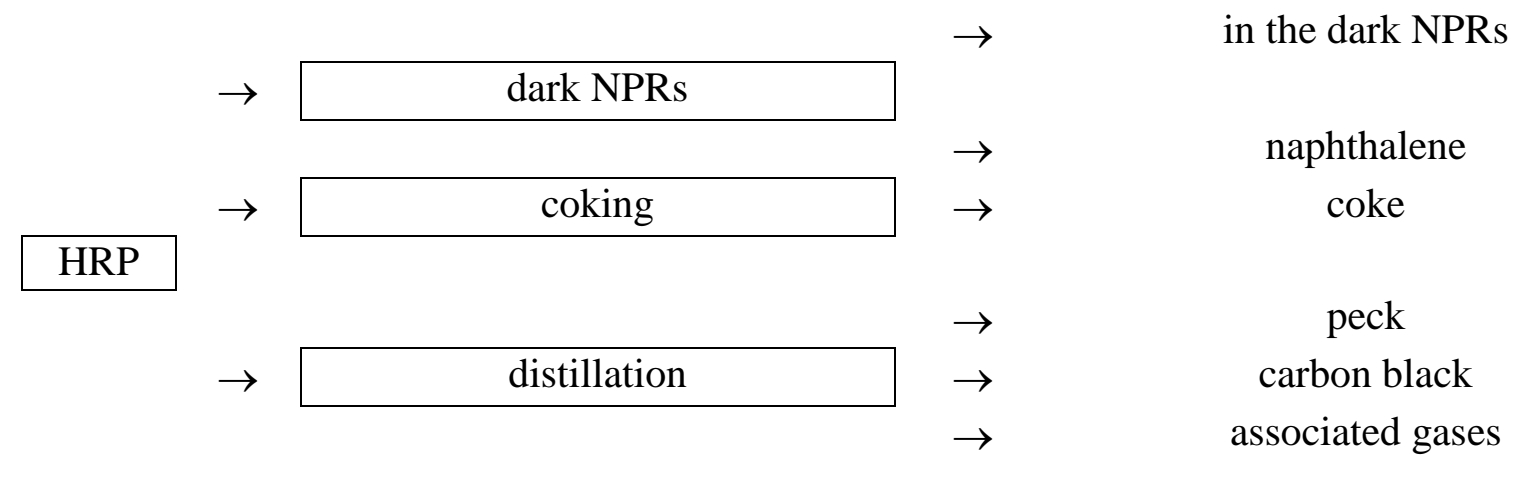

\begin{tabular}{|l|l|l|l|}
\hline & & $\rightarrow$ & naphthalene, tetralin \\
\hline & & $\rightarrow$ & alkylnaphthalenes \\
\hline & & $\rightarrow$ & acenaphthene, fluorine \\
\hline & & $\rightarrow$ & motor fuel \\
\hline & $\rightarrow$ & $\rightarrow$ & raw material for carbon black \\
\hline & & $\rightarrow$ & raw materials for electrode coke \\
\hline & & $\rightarrow$ & raw materials for electrode pitch \\
\hline & & $\rightarrow$ & raw materials for needle coke \\
\hline & & $\rightarrow$ & dark NPRs \\
\hline
\end{tabular}




\section{Conclusion}

Such complex processing of liquid pyrolysis products allows to significantly reduce the amount of waste products of oil refining and its fractions and increase the efficiency of production. Introduction into production of the offered products will allow to receive valuable substances from secondary raw materials.

\section{References}

[1.]Zohuriaan-Mehr, M. J., \& Omidian, H. (2000). Petroleum resins: an overview. Journal of Macromolecular Science, Part C: Polymer Reviews, 40(1), 23-49.

[2.]Mildenberg, R., Zander, M., \& Collin, G. (2008). Hydrocarbon resins. John Wiley \& Sons. 